\title{
Research on the Development Strategies of Yunnan' Historic and Cultural Tourism Resources
}

\author{
Yiqiu Wang ${ }^{1,}$, Shijie $\mathrm{Li}^{1, \mathrm{~b}}$ \\ (' Zhao Tong University,Zhaotong city in Yunnan province,China,657000) \\ aemail, ${ }^{\mathrm{b}}$ email
}

Keywords: Yunnan, Historic and cultural tourism, Tourism resources

\begin{abstract}
The long and rich history and culture of Yunnan are important resources for tourism development in Yunnan. The Yunnan' historic and cultural tourism resources are unique, rich in categories and relatively complete preservation. In the process of the development of historical and cultural tourism resources in Yunnan, we should try our best to pay attention to the strategies of government orientation, mass participation, media promotion and resources conservation to provide more attractive tourism products and services for the tourists.
\end{abstract}

\section{Introduction}

As a frontier province in southwest of China, Yunnan is not only a province with many nationalities, but also has a long history. More than 2000 years of history of civilization of Yunnan creates and nurtures a rich and bright humanistic culture. These humanistic culture through the years of erosion and accumulation of history, condensed into a rich historical and cultural resources. Effective protection and rational use of Yunnan's historical and cultural resources is not only an important topic and task of contemporary Yunnan cultural construction, but also an important way to promote the development of tourism industry and cultural industry in Yunnan. From the development of tourism industry in Yunnan, in recent years, through the effective development and successful marketing of Yunnan rich and colorful, unique tourism resources, the tourism industry in Yunnan has achieved rapid development of ultra-conventional, Yunnan become a major tourism province famous at home and abroad. At present, the development of tourism in Yunnan is mainly dependent on various types of tourism resources and environment and the development of scenic spots, in order to attract tourists, tourism destination for the creation of tourism revenue, is a resource-based industry. In order to deepen the sustainable development of Yunnan's tourism industry, it has made remarkable growth in the short term. The growth of tourist volume is directly proportional to the quality and characteristics of tourism resources. The development of tourism industry, the choice of regional tourism resources is the key, the region is not attractive. One of the key factors that influence the attraction of tourist destination is the characteristic culture. Therefore, it is necessary to strengthen the cultural connotation of resources in order to enhance the attraction of tourist resources in Yunnan. We focus on the development of cultural tourism products, especially the development of cultural tourism resources. It has a great relationship with the requirements of the lasting vitality and attraction of tourism products and the improvement of the cognitive level of tourism.

\section{Contents and Features of Historic and Cultural Tourism Resources in Yunnan}

Contents. The historical culture of Yunnan is the integration and summation of the different periods of culture and the different fields in the process of the development of Yunnan's history. From the point of view of tourism, tourism resources are the things and factors that attract tourists in nature and human society. Things and factors of economic benefit and social benefit. Tourism resources can be divided into two categories: natural tourism resources and cultural tourism resources. The concept of Yunnan historical and cultural tourism resources, development of our tourism industry from the contemporary perspective of Yunnan historical and cultural content of the value judgment and understanding, which is the history of Yunnan culture as tourism resources with elements of tourism 
development value, can bring social benefits to the real economy. From the point of view of the resources, the historical and cultural tourism resources in Yunnan can be divided into two categories: material form, historical and cultural tourism resources and non-material historical and cultural tourism resources. The material form of historical and cultural tourism resources mainly refers to various historical and cultural relics, objects, sites and monuments, such as various types of unearthed artifacts, cultural relics, ancient ruins, ancient buildings, cave temples, stone carving, cliff painting. Nonphysical forms of historical and cultural tourism resources mainly refer to the kind of non-historical and cultural information, such as historical events, historical legends, historical stories, historical relic, the historical and cultural information mainly through literature word-of-mouth legend and folk customs and heritage preservation. The historical and cultural tourism resources in the form of material are direct and dominant tourism resources. Yunnan historical and cultural tourism resources is the entity content rich cultural and historical resources of Yunnan's tourism development value and prospects for tourism development of Yunnan historical and cultural resources is the basic function of Yunnan historical and cultural tourism resources.

Features. Yunnan' national culture has its unique connotation. The province's ethnic, social, economic, historical, and cultural development is uneven, which determines the country's national culture presents a colorful, colorful features. Yunnan area since the six or seven century BC has entered the age of civilization, the process of historical culture has been continuously. Although there were wars and conflicts, but the development of social economy has not suffered major damage and disruption, therefore Yunnan area rich historical and cultural heritage, various periods of various historical and cultural, historical and cultural preservation and heritage has certain historical and cultural resources are very rich. Only in terms of cultural relics and historic sites, Yunnan is one of the provinces with rich cultural relics in china. Yunnan is a minority area culture is very rich, although tens of years of development, but there are still many things not fully demonstrated, and we also pay attention to the protection of the development, development is still the depth of the development of space. All ethnic groups in Yunnan have created their own ancient culture in the course of history. Because it is located in the remote and blocking traffic, so that the ancient culture is more complete than the original pure preserved. Dai ethnic customs and ancient songs, ancient music, ancient dance are called living fossil culture. The history and culture of Yunnan is created by the people of all ethnic groups living in Yunnan. In this sense, the history and culture of Yunnan is actually a collection of the history and culture of the ethnic groups in Yunnan. Due to geographical differences and historical development, in the long history of evolution, the history of the Yunnan region culture has formed obvious geographical differences, sub regional history and culture which formed the distinctive.

\section{Development Strategies of Yunnan' Historic and Cultural Tourism Resources}

Government Orientation. We adhere to the government led, not on. The leading function of the government is mainly reflected in the decision making of the products, the overall planning, to avoid duplication of construction and abuse of Yunnan historical and cultural tourism resources development. Especially in the early stage, we should be in the premise of the implementation of entrepreneurship in Yunnan tourism development, in the mechanism of the development of tourism, the Yunnan provincial government should play the role of guidance and coordination. The government has given special policies to further develop the tourism market, so that enterprises become market players. All levels of government collaboration are the key to build tourism corridor We need to play together to create the need to establish tourism and service concept, to establish more benefit sharing principle, rationality in terms of accessibility the road traffic line, provide operational conditions, common to create a cultural tourism brand. The government should attach importance to the development of the theme, increase the cultivation of market players. As a consumer goods, cultural tourism cannot be separated from the brand, packaging, marketing planning and marketing. The provincial government in the valley of minority culture tourism in the overall promotion of great responsibility. It has the government and tourism organization state and county irreplaceable influence, the government led corporate body, and the parties to the joint operation of the market 
pattern promotion work will be of actual or potential customers to launch a powerful propaganda offensive. Yunnan provincial government implements famous brand tourism product strategy. The theme of tourism development is that we should try to grasp and strengthen the development of the strongest and most valuable development context. The theme of tourism project development should be based on history and culture.

Mass Participation. Yunnan province tourism resources are widely distributed in mountainous and semi mountainous area economic development lags behind, the fragile ecological environment in ethnic minority areas, but also the traffic is relatively closed, people ideology and values of the backward regions. From these places in the tourism development issues, is the main resource holders of low cultural quality, economic capital is weak, and lack of business minded management skills, making the development of the construction and management of most tourism lack of community participation or community participation degree is low. Although the tourism industry has achieved great development in many places, but as the main body of the community and the owner of the resources are often excluded from the development of tourism, has become a spectator. They cannot fully share the economic benefits brought by tourism development in tourism development. Therefore the development of tourism projects to get sustained and effective community support, finally in turn affect the protection and preservation of national culture nature and the humanities environment influence to the tourist area, endangering the sustainable development of tourism. Yunnan province put forward the slogan of national tourism. Its meaning is profound, highlighting the people's basic role and support for tourism. However, it does not mean that the herd and out of order development, but in key areas, the most extensive and in-depth mobilization of the people involved in the excavation and protection of historical and cultural resources, based on the local residents' education, cultivate and heighten the strong cultural atmosphere. In order for the commercial outlets, a good public environment, not only the simplicity of folk customs and cultural traditions have commercial interests and maximize the fusion, to create the most suitable conditions for the spread of culture, and gives its vitality.

Media Promotion. Yunnan ethnic cultural tourism resources and tourism products on the basis of development, continue to cause the attention of people, and have good social and economic benefits, must have the aid of newspapers and magazines, radio and television and other media, the use of modern high-tech means, such as the establishment of information platform, web site, web system, carry out tourism promotion application the Internet and other media, all-round, multi-channel, high density to carry out tourism promotion work in this area in Yunnan has made great achievements. The site also released a series of reports on Yunnan's tourism has played a great role in publicity. But on the whole, Yunnan in the use of media issues, did not pay attention to the study of opponents, for the right to speak. Such as the concept of speculation, we seize the opportunity to do every successfully. Too much publicity is helpless to the growth and development of culture and culture, will also give visitors to spread some incorrect information, distort the traditional culture, the resource owners and their offspring is not fair, because they will be in such a bad publicity and mislead the adverse effect in the development of. Instead, we should adhere to the goal of sustainable tourism and promote the understanding of the economic and environmental effects of tourism. Therefore, the promoters should be clear about what can and should be displayed to visitors and vigorously promote, which cannot be displayed to visitors and should be imprisoned. We must make clear how to develop and display in order to promote the development of traditional culture and promote the development of culture at the same time to reduce and avoid the impact of national culture due to open to tourists.

Resources Conservation. We want to develop historical and cultural tourism resources, starting from the unique historical and cultural tourism resources, highlighting the characteristics of resources in a more distinctive theme. The Yunnan provincial government has launched the related tourism activities around this issue, reducing the homogeneity with other competitive resources, thus forming a unique competitive power. First of all, the regional tourism resources developers and cultural management departments should start from the protection of historical and cultural tourism resources perspective, in the cultural industry development of the deeper guidance characteristics of historical and cultural tourism resources of mining. At the same time, it is necessary to carry out a full 
investigation of the market, through the analysis of the tourism market coverage, demand characteristics, development trends and other issues, the establishment of a unique competitive tourism industry. Finally, it is necessary to explore the unique cultural connotation of resources through the rational analysis of resources, to extract the cultural characteristics of the most suitable for the characteristics of resources, as the theme, to guide other tourism activities. It is helpful for the development of tourism resources, but also to attract more tourists, and to meet the needs of tourism. Only by combining the tourists with tourism resources, and digging up the connotation of historical and cultural tourism resources, tourists can appreciate the charm of historical and cultural tourism resources more fully. Therefore, to the development of historical and cultural tourism resources need to start from the perspective of authenticity, protection of resources, through a series of reasonable tourism activities for visitors to participate in the historical and cultural scene, increase interaction and experience, the experience is closer to the true history of the environment, in order to fully meet the needs of tourism.

\section{Conclusion}

The urban structure, street blocks or ethnic customs in today's Yunnan have inherited and continued a lot of historical and cultural elements. They are the tourism resources of high level in Yunnan needing to be developed. We should have scientific, systematic planning and development strategies of these high-quality resources to create a unique brand of tourism and enhance the development of tourism in Yunnan province.

\section{References}

[1] Xiao Honglei, Zhang Yunsong, Research on National Cultural Tourism Development Strategies in Luquan County of Yunnan Province [J]. Journal of Yunnan Agricultural University (Social Science), 2016, 10(3): 67-71.

[2] Wang Jiaying, Zhu Xiaohui, Research on the Development of the National Cultural Creative Tourism - take Yunnan as an example [J]. Special Zone Economy, 2016(12): 131-132.

[3] Chen Wenxing, Development of Wa Cultural Tourism Resources in Yunnan Province [J]. Journal of Anhui Agricultural Sciences, 2016, 44(30): 142-145.

[4] Deng Alan, Zhao Hongmei, The Tourism Development of Intangible Cultural Heritage in Yunnan Province - a Case of Kunming Diao, 2012(8): 12-14. 